\title{
Airway blood flow and bronchovascular congestion in sheep
}

\author{
E.M. Baile*, A. Sotres-Vega**, P.D. Paré*
}

Airway blood flow and bronchovascular congestion in sheep. E.M. Baile, A. SotresVega, P.D. Paré. OERS Journals Ltd 1994.

ABSTRACT: Vascular congestion could play an important role in causing airway narrowing in asthma. However, the effects of altered bronchial vascular volume and blood flow on airway morphology and pulmonary resistance have not been studied. The aim of this study was to measure airway calibre and vascular volume during inhalation of reputed dilators and constrictors of the airway vasculature in sheep.

After baseline measurements of pulmonary resistance $\left(R_{L}\right)$ and airway blood flow (Q்w), anaesthetized sheep inhaled an aerosol of either: $0.9 \%$ saline $(n=6)$; histamine $16 \mathrm{mg} \cdot \mathrm{ml}^{-1}(\mathrm{n}=5)$; phenylephrine $0.1-10 \mathrm{mg} \cdot \mathrm{ml}^{-1}(\mathrm{n}=6)$, or methoxamine $1 \mathrm{mg} \cdot \mathrm{ml}^{-1}(\mathrm{n}=5)$. $R_{L}$ and $\dot{Q}$ aw were measured at the time of peak bronchoconstriction, and the sheep were rapidly killed and lung blood loss prevented. Right lung Q aw was calculated and left lung processed for histology; measurements of cartilaginous airway size, wall thickness and fraction of the wall occupied by blood were made using morphometric techniques.

Results showed that $20-30 \%$ of the airway wall was occupied by blood vessels. Inhalation of histamine caused an increase in $\dot{Q} a w$ and $R L$, and a $50 \%$ increase in the vascular volume fraction of the airway wall, whereas inhaled alpha-agonists did not reduce $\dot{Q}$ aw or vascular volume fraction.

We conclude that the major cause of airway narrowing after inhalation of histamine is contraction of the smooth muscle, and the bronchovascular congestion contributes little to airway narrowing in cartilaginous airways of sheep. In addition inhaled alpha-agonists do not constrict the bronchial microvasculature under baseline conditions. Therefore, our results do not support the hypothesis that protection against bronchoconstriction provided by alpha-agonists is due to vasoconstriction. Eur Respir J., 1994, 7, 1300-1307.

\author{
*University of British Columbia Pulmonary \\ Research Laboratory, St. Paul's Hospital, \\ Vancouver, BC, Canada. **Instituto Nacional \\ de Enfermedades Respiratorias, Tlalpan, \\ DF, Mexico.
}

Correspondence: E. Baile

UBC Pulmonary Research Laboratory

1081 Burrard Street

Vancouver

BC V6Z 1 Y6

Canada

Keywords: Airway calibre

bronchial blood flow

bronchovascular volume

morphometry

pulmonary resistance

radioactive microspheres

Received: July 121993

Accepted after revision January 301994

Supported by a grant from the Canadian International Development Association. EMB was supported by The Heart \& Stroke Foundation of $\mathrm{BC}$ and Yukon.
There is considerable indirect anatomical and physiological evidence to suggest that the bronchial vasculature can influence airway wall thickness and luminal calibre. The bronchial vascular bed consists of two interconnecting capillary networks - a peribronchial plexus and a subepithelial plexus [1-3]. In many species (sheep, rabbits and humans) there is also a system of conspicuous sinuses in the tracheobronchial mucosa $[4,5]$. Increased permeability and/or engorgement of the bronchial vessels could lead to airway wall thickening and luminal narrowing. LAITINEN et al. [6] have shown that parasympathetic nerve stimulation and vasodilator drugs, such as histamine and methacholine, increase mucosal thickness in the dog's trachea, whereas the constrictor drug, phenylephrine, decreases mucosal thickness.

Morphometric techniques have also been used to assess the potential contribution of the bronchial vasculature to airway narrowing. MARIASSY et al. [7] have shown that when the bronchial vasculature is dilated it can occupy up to $30 \%$ of the submucosal tissue volume. KuwANO et al. [8] counted the number of bronchial vessels and the area occupied by bronchial vessels in the airways of patients who had asthma and chronic obstructive lung disease. Patients who had fatal asthma showed an increase in the number and size of their bronchial vessels. JAMES et al. [9] have shown an increased number of bronchial venules in cartilaginous airways of asthmatic subjects, when compared to those of control subjects.

The results from several clinical studies also provide indirect evidence that vascular congestion and oedema could play an important role in causing the airway narrowing associated with asthma induced by exercise and isocapnic hyperventilation [10-12], and the airway hyperresponsiveness observed in patients who have pulmonary venous hypertension [13, 14].

Despite this indirect evidence, no actual measurements have been made of the effects of altering bronchial vascular volume and blood flow on airway wall thickness, airway calibre and pulmonary resistance. Therefore, we nebulized reputed dilators and constrictors of the bronchovasculature in anaesthetized sheep and measured airway blood flow, using radioactive microspheres. Pulmonary resistance was used as an index of airway calibre, and morphometric techniques were used to assess changes in airway wall thickness and tracheobronchial blood volume. 


\section{Methods}

Twenty two Dorset-cross rams weighing $41 \pm 4 \mathrm{~kg}$ were studied. All studies were performed according to the guidelines of the Helsinki convention for the use and care of animals. Sheep were anaesthetized by intravenous injection of thiopental $\left(15-20 \mathrm{mg} \cdot \mathrm{kg}^{-1}\right)$ and placed in the supine position; a tracheostomy tube was inserted just below the larynx and the sheep were ventilated using a tidal volume of $12-15 \mathrm{ml} \cdot \mathrm{kg}^{-1}$ and a rate of 15 breaths $\cdot \mathrm{min}^{-1}$. Anaesthesia was maintained using 1-2\% halothane in $50 \%$ air and oxygen. Catheters were inserted into the right femoral vein and artery to administer fluids and to obtain a reference flow blood sample, respectively; and into the left carotid artery for measurement of systemic arterial blood pressure and to take blood samples to measure arterial blood gas tensions. A thermistor-tipped, triple lumen catheter was inserted, under fluoroscopic control, through the right jugular vein into the left main pulmonary artery for measurement of pulmonary arterial pressure and determination of cardiac output, using the thermodilution technique. An 8 French balloon-tipped (volume $4 \mathrm{ml}$ ) catheter was inserted into the right jugular vein and positioned in the right main pulmonary artery. This balloon was inflated to transiently block the right pulmonary artery during injection of the microspheres, to prevent any recirculation of the microspheres to the right lung. All vascular pressures were referenced to the level of the left atrium.

The chest was opened using a median sternotomy incision, and $3 \mathrm{cmH}_{2} \mathrm{O}$ positive end-expiratory pressure was applied. A $3 \mathrm{~mm}$ diameter catheter was inserted into the left atrial appendage for later injection of radioactive microspheres. A loose tie was placed around the hilum of the left lung. A short section of the trachea $(\sim 5 \mathrm{~cm})$, with no obvious blood vessels supplying it, was freed of surrounding tissue and ties were placed loosely around the lower and upper sections of this segment.

To calculate pulmonary resistance, we measured airflow using a pneumotachometer coupled to a differential pressure transducer, and changes in volume were calculated by electrical integration of the flow signal; tracheal pressure was measured, using a differential pressure transducer (Validyne $45 \mathrm{MP} \pm 100 \mathrm{cmH}_{2} \mathrm{O}$ ). Pulmonary resistance $\left(\mathrm{RL}, \mathrm{cmH}_{2} \mathrm{O} \cdot l^{-1} \cdot \mathrm{s}\right)$ was measured at an oscillatory frequency of $4-6 \mathrm{~Hz}$, using the electrical subtraction method of MEAD and WhITTENBERGER [15].

Sheep were divided randomly into four groups, as follows. Group 1, $(n=6)$ served as controls. After recording baseline measurements, as described below, each sheep received an aerosol of $2 \mathrm{ml}$ (total volume in nebulizer was $4 \mathrm{ml}$ ) of nebulized $0.9 \%$ saline delivered by an acorn nebulizer driven at a flow rate of $5 \mathrm{l} \cdot \mathrm{min}^{-1}$, using $100 \%$ oxygen as the gas source. Sheep in the other three groups received an equivalent volume of nebulized solution. Group 2, $(n=5)$ received an aerosol of nebulized histamine solution $\left(16 \mathrm{mg} \cdot \mathrm{ml}^{-1}\right)$. Group $3,(\mathrm{n}=6)$ received an aerosol of nebulized phenylephrine solution ( 2 sheep, $0.1 \mathrm{mg} \cdot \mathrm{ml}^{-1} ; 2$ sheep, $0.5 \mathrm{mg} \cdot \mathrm{ml}^{-1} ; 2$ sheep, $10 \mathrm{mg} \cdot \mathrm{ml}^{-1}$ ). Pilot dose-response curves showed an increase in systemic arterial blood pressure in response to the higher dose of phenylephrine. Group 4, $(n=5)$ received an aerosol of nebulized methoxamine solution $\left(1 \mathrm{mg} \cdot \mathrm{ml}^{-1}\right)$. This dose was determined from the results of a pilot study, in which we gave increasing concentrations of aerosolized methoxamine $\left(0.5,1\right.$ and $\left.5 \mathrm{mg} \cdot \mathrm{ml}^{-1}\right)$. Inhalation of $5 \mathrm{mg} \cdot \mathrm{ml}^{-1}$ produced systemic effects: namely, an increase in systemic arterial blood pressure, heart rate and cardiac output. No systemic effects were noted during inhalation of $1 \mathrm{mg} \cdot \mathrm{ml}^{-1}$ methoxamine.

\section{Experimental protocol}

After the surgery and when physiological variables were stable, we recorded baseline measurements of systemic and pulmonary arterial pressure, pulmonary arterial wedge pressure, cardiac output, arterial blood gas tensions, pulmonary resistance and dynamic compliance. For Groups 2, 3 and 4, systemic blood flow to the right lung and trachea was measured as follows: firstly, the balloon in the right main pulmonary artery was inflated and its correct position verified by fluoroscopy; at time 0 a femoral arterial reference flow blood sample was withdrawn over a 2 min period, by use of a withdrawal pump set at a rate of $10 \mathrm{ml} \cdot \mathrm{min}^{-1}$. Ten seconds after starting the pump, $3.6 \mathrm{MBq}$ of ${ }^{85} \mathrm{Sr}$-labelled microspheres $\left(>6 \times 10^{6}\right.$ spheres, $15 \pm 2 \mu \mathrm{m}$ diameter) suspended in $5 \mathrm{ml} 0.9 \%$ saline, were injected as a bolus into the left atrial appendage. After collection of the reference flow sample, the balloon in the right pulmonary artery was deflated.

After completion of the baseline measurements, each sheep received an aerosol of the selected agent. Pulmonary resistance was measured before (time 0 ) and at 1,5 and $30 \mathrm{~min}$ after aerosol administration. The time of peak response of pulmonary resistance (between 3-5 min after the end of nebulization of histamine) to the aerosolized drug was noted. When the physiological parameters of each sheep had returned to baseline values, generally within an hour, haemodynamics, arterial blood gas tensions, pulmonary airway resistance and compliance were measured again. Sheep were subjected to another dose of the nebulized aerosol and, for the histamine group, the second measurement of systemic blood flow (2.6 $\mathrm{MBq}{ }^{153} \mathrm{Gd}$-labelled microspheres) was made to coincide with the time of peak response in pulmonary resistance, as previously noted during the first nebulization of the aerosol. Because there was no systematic change in pulmonary resistance in response to inhalation of phenylephrine or methoxamine, and the effect of the alpha-agonists is short-acting, the second measurement of blood flow was made after 5 min of inhalation of the alpha-agonists.

Immediately after blood flow had been measured, the experiment was rapidly terminated: special care was taken to prevent loss of blood volume from the tracheal segment and the left lung. This was achieved as follows: firstly, the upper and lower ligatures around the tracheal segment were tied firmly (a modified tracheal cannula had been carefully positioned within the region of trachea to be sampled; both ends of the cannula were solid tubing and the central portion was fenestrated, permitting ligation of the tracheal segment without collapsing it and 
at the same time allowing contact of the central portion by the fixation fluid). Secondly, and simultaneously, the ventilator was turned off at end-inspiration, the ligatures around the left hilum were tied tightly, and saturated potassium chloride was injected into the heart via the left atrial appendage.

\section{Tissue preparation}

The lungs and trachea were carefully excised. The tracheal segment was fixed by immersion in 10\% formaldehyde solution for $24 \mathrm{~h}$. It was then removed, and five 1-2 mm thick cross-sections were cut from sequential tracheal rings. The rings were embedded in paraffin, sectioned and stained using Masson's trichrome. The left lung was immediately immersed in $-70^{\circ} \mathrm{C}$ liquid nitrogen and rapidly frozen. It was then removed and 4-6 $1 \mathrm{~cm}$ thick, sagittal sections were cut using a band-saw. The slices of lung were placed in a $750 \mathrm{ml}$ container of precooled acetone $\left(<-70^{\circ} \mathrm{C}\right)$. The container and lung slices were then returned to the $-70^{\circ} \mathrm{C}$ freezer. They were removed the following day and allowed to remain at room temperature for at least $24 \mathrm{~h}$. Seven $1 \mathrm{~mm}$ thick sections were cut from the lung slices, care being taken to ensure that cross-sections of peripheral and central cartilaginous airways were obtained. The samples were put into cassettes and placed in acetone at room temperature. They were embedded in paraffin, sectioned and stained with Masson's trichrome.

\section{Blood flow}

The right lung (excluding the cranial lobe) and remaining trachea were dissected to permit measurement of flow to the following regions: tracheal mucosa; mainstem, lobar and segmental bronchi; and central and peripheral parenchymal tissue. All lung and reference flow blood samples were placed in preweighed scintillation vials, reweighed to obtain the wet weight, and placed in a Beckman 8,000 gamma counter. The radioactivity of the samples was counted and correction made for gamma spectrum overlap, background counts and radioactive decay. Tracheal mucosal and right lung blood flow were calculated, as described previously [16].

\section{Blood flow $\left(\mathrm{ml} \cdot \mathrm{min}^{-1}\right)=$ At/Af $x$ Qref}

where At and Af are the radioactive counts in the lung tissue and reference flow blood sample, respectively, and Qref is the reference flow rate in $\mathrm{ml} \cdot \mathrm{min}^{-1}$. Flow to each region was also expressed per $100 \mathrm{~g}$ of tissue, by dividing the flow to each region by the tissue's wet weight and multiplying by 100 .

\section{Morphometric measurements}

We examined tracheal cross-sections and peripheral and central cartilaginous airways that had been cut in cross-section (short:long diameter $>0.6$ ). Morphometric measurements were made by an observer who was blind with respect to the grouping of the histological slides.
A total of 266 airways (Group 1, n=67; Group 2, n=37; Group $3 n=75$; Group $4 n=87$ ) were examined. Measurements were made using a Nikon microscope equipped with a camera lucida attachment and a digitizing tablet coupled to an Apple IIe computer. The measurements made for the cartilaginous bronchi were: 1) airway internal perimeter $(\mathrm{Pi})$ and area $(\mathrm{Ai})$, defined by the luminal border of the airway epithelium; 2) airway smooth muscle perimeter ( $\mathrm{Pm})$ and area $(\mathrm{Am})$, defined by the outermost layer of airway smooth muscle; and 3) airway outer perimeter ( $\mathrm{Po})$ and area (Ao), defined by the adventitial border. The measurements made for the trachea were: $\mathrm{Pi}, \mathrm{Ai}, \mathrm{Po}$ and Ao; Po being the junction between the mucosa and the perichondrial layer. Inner wall area was defined as the area of the wall internal to the outermost layer of smooth muscle (Am-Ai). Outer wall area (adventitial area) in bronchi was defined as the area between the outermost layer of smooth muscle and the surrounding lung parenchyma (Ao-Am).

Point counting was performed on the tracheal sections to determine the percentage of wall occupied by blood vessels, and on the cartilaginous airway sections to determine the percentage of wall occupied by blood vessels, smooth muscle and cartilage. For the purpose of calculating the percentage of the wall occupied by blood vessels, the airway was divided into the inner wall and the outer wall (as defined above). To test intraobserver reproducibility, measurements of airway wall areas were repeated in 30 airways, and the difference between the two measurements was divided by the average value of the two measurements and expressed as a percentage.

\section{Data analysis}

All data are expressed as mean values \pm sem. A p-value less than 0.05 was taken to be statistically significant. A two-way analysis of variance (ANOVA) was used to test for differences between groups in physiological variables; one factor for the ANOVA was the repeated measures "time" and the other was the "experimental group". A Bonferroni adjustment was made for multiple comparisons. Airway size was determined from the length of the internal perimeter $(\mathrm{Pi})$, and the area of the airway wall and its components were converted to their square root to linearize the relationship to Pi $[17,18]$.

The restricted maximal likelihood technique of FeLDMAN [19] was used to examine the relationship between airway wall area and airway size. This technique is an effective way to analyse this relationship because of the way random effects are dealt with; within-sheep variation is separated from between-sheep variation and consistent between-sheep trends can be detected. Because multiple measurements from one sheep are not independent observations, it is not appropriate to pool the data and form a single regression line for the group. The Feldman technique [19] is based on the assumption that the individual slopes and intercepts within a group are normally distributed around some mean value. Each sheep's data is weighted according to how well they fit the relationship, and an iterative process is used to minimize the variance of the slopes and intercepts. This 
method allows the calculation of average relationships for each group, and the establishment of confidence intervals for the relationships. Significance levels can be determined for the difference between the slopes, intercepts, and regression lines. To detect airway luminal narrowing we plotted $\mathrm{Ai}$ against $\mathrm{Pi}$ for each group, and compared the relationship using the same analysis [19].

\section{Results}

\section{Haemodynamics and arterial blood gas tensions}

There was no difference between groups, before and $30 \mathrm{~min}$ after nebulization, in measurements of vascular pressures, cardiac output and arterial blood gas tensions. Mean values \pm SEM for these parameters for all groups are shown in table 1.

\section{Pulmonary resistance}

There was no differences between groups in baseline values of pulmonary resistance. Aerosolized histamine produced more than a two fold increase in resistance 5

Table 1. - Haemodynamics and arterial blood gases before and after nebulization $(n=22)$

\begin{tabular}{lccc}
\hline & Before & After \\
\hline $\mathrm{BP} \mathrm{cmH}$ & & \\
$\mathrm{Ppa} \mathrm{cmH}_{2} \mathrm{O}$ & $94 \pm 3$ & $93 \pm 3$ \\
$\mathrm{CO} l \cdot \mathrm{min}^{-1}$ & $11 \pm 0.4$ & $11 \pm 0.3$ \\
$\mathrm{pH}$ & $3.5 \pm 0.2$ & $3.7 \pm 0.1$ \\
$\mathrm{Paco}_{2}$ & $\mathrm{mmHg}$ & $7.42 \pm 0.01$ & $7.43 \pm 0.01$ \\
& $(\mathrm{kPa})$ & $38 \pm 0.6$ & $38 \pm 0.6$ \\
$\mathrm{PaO}_{2}$ & $\mathrm{mmHg}$ & $(5.1 \pm 0.1)$ & $(5.1 \pm 0.1)$ \\
& $(\mathrm{kPa})$ & $186 \pm 1$ & $143 \pm 7$ \\
& & $(24.8 \pm 0.1)$ & $(19.1 \pm 0.9)$ \\
\hline
\end{tabular}

Data are presented as mean \pm SEM. BP: systemic arterial blood pressure; Ppa: pulmonary arterial pressure; $\mathrm{CO}$ : cardiac output; $\mathrm{PaCO}_{2}$ : arterial carbon dioxide tension; $\mathrm{PaO}_{2}$ : arterial oxygen tension.

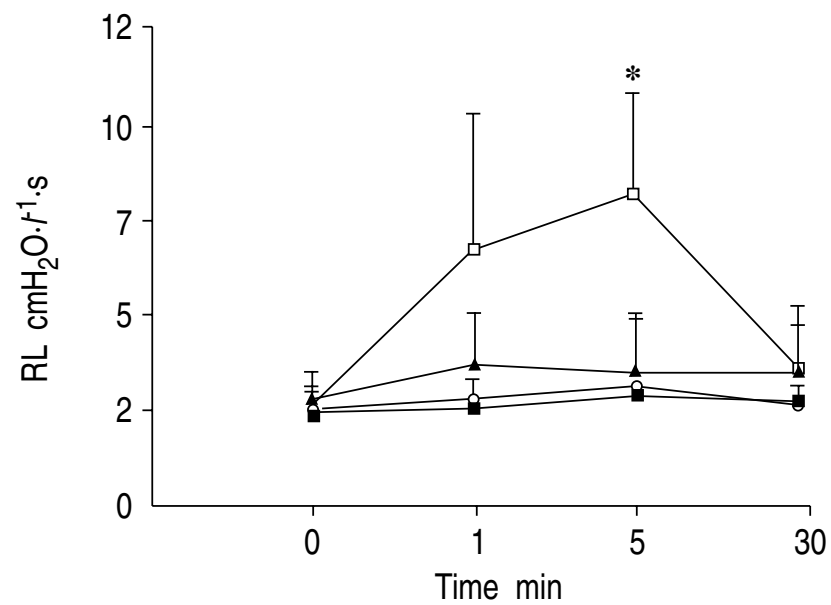

Fig. 1. - Pulmonary resistance (RL) before (time 0 ) and at 1, 3, 5 and 30 min after inhalation of an aerosol of saline (control, $n=6$ ), histamine $(n=5)$, phenylephrine $(n=6)$ and methoxamine $(n=5)$. Data are presented as mean \pm SD. *: $\mathrm{p}<0.01$, different from baseline. - saline; - $\longrightarrow$ - : histamine; $\longrightarrow-$ : phenylephrine; $\longrightarrow$ : methoxamine. min after stopping inhalation of the drug $(\mathrm{p}<0.01)$ (fig. 1). However, there were no changes in resistance after inhalation of phenylephrine or methoxamine.

\section{Blood flow}

There were no differences between Groups 2, 3, and 4 in baseline values of blood flow to the tracheal mucosa, peripheral or central airways (fig. 2). Nebulized histamine produced more than a two fold increase in tracheal mucosal $(\mathrm{p}<0.05)$, and central airway $(\mathrm{p}<0.05)$, blood flow but no change in peripheral airway blood flow. There were no changes in flow to any of these regions after nebulized phenylephrine or methoxamine.

a)

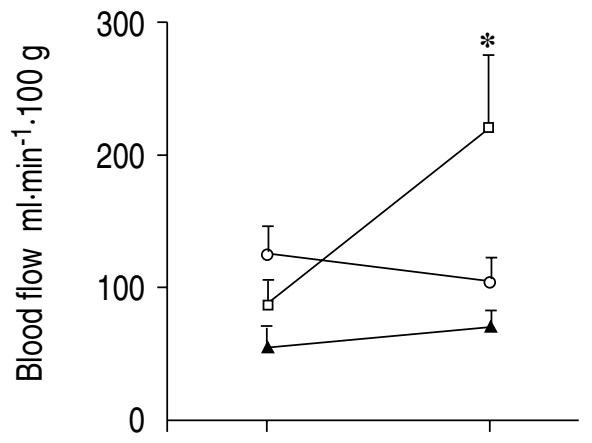

b)

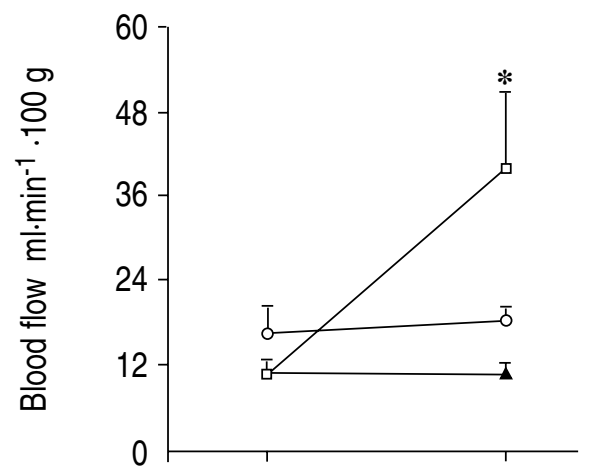

c)

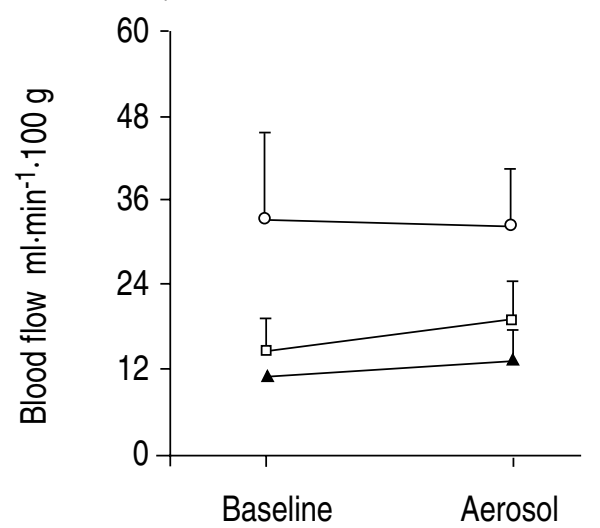

Fig. 2. - Changes in: a) tracheal mucosal blood flow; b) central; and c) peripheral airway blood flow, before and after inhalation of an aerosol of histamine $(n=5)$, phenylephrine $(n=6)$ and methoxamine $(n=5)$. Data are presented as mean \pm sEM. $*: \mathrm{p}<0.05$, different from baseline. $\longrightarrow-$ : histamine; $\multimap-$ : phenylephrine; $\multimap$ : methoxamine. 


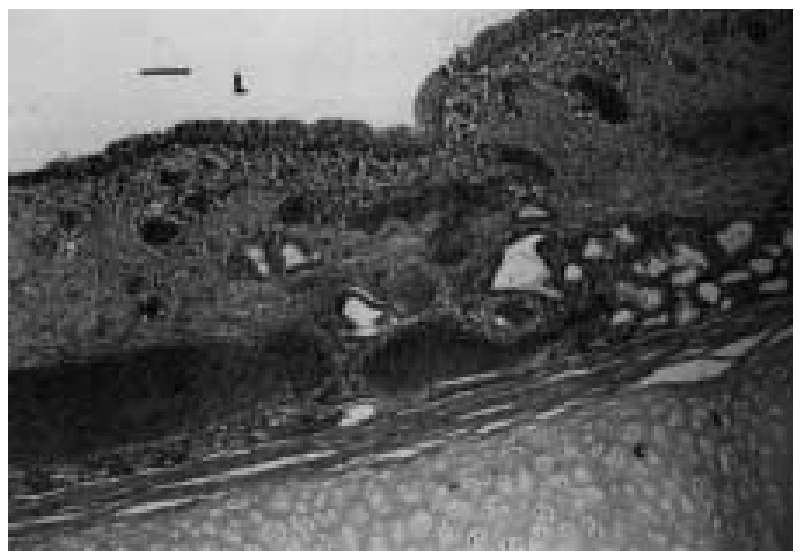

Fig. 3. - Photomicrograph showing cross-section of a trachea (control group). L: tracheal lumen; c: cartilage; v: blood vessels, occupying a considerable proportion of the mucosal area. ( $\times 20$ magnification). Bar length is $80 \mu \mathrm{m}$.

Table 2. - Cartilaginous intraparenchymal airways; percentage of the airway wall occupied by blood vessels and smooth muscle (inner wall), blood vessels and cartilage (outer wall), and blood vessels (total wall)

\begin{tabular}{lcccc}
\hline & Group 1 & Group 2 & Group 3 & Group 4 \\
\hline Inner wall & & & & \\
Blood vessels & $15 \pm 1$ & $24 \pm 4^{*}$ & $18 \pm 2$ & $19 \pm 6$ \\
Smooth muscle & $24 \pm 3$ & $19 \pm 4$ & $26 \pm 1$ & $18 \pm 2$ \\
Outer wall & & & & \\
Blood vessels & $21 \pm 2$ & $31 \pm 6^{*}$ & $25 \pm 4$ & $27 \pm 6$ \\
Cartilage & $36 \pm 6$ & $33 \pm 5$ & $35 \pm 7$ & $36 \pm 6$ \\
Total wall & & & & \\
Blood vessels & $18 \pm 2$ & $28 \pm 5^{*}$ & $23 \pm 3$ & $25 \pm 5$ \\
\hline
\end{tabular}

Data are presented as mean \pm SEM. *: $\mathrm{p}<0.01$, different from control (Group 1).

\section{Morphometry}

There was close intraobserver reproducibility of morphometric measurements of airway wall areas. The average percentage variation (SEM) between two measurements for $\mathrm{Ai}, \mathrm{Am}$ and Ao was $0.9 \pm 0.16,1.8 \pm 0.33$ and $5.9 \pm 1.1 \%$, respectively.

A photomicrograph of a cross-section of a trachea is shown in figure 3 , to illustrate the substantial contribution made by the blood to tracheal mucosal volume. In Group 1 (control) blood vessels occupied $34 \pm 10 \%$ of the tracheal submucosa; this percentage was not different in the other three groups (Group 2: $30 \pm 6 \%$; Group 3: $34 \pm 8 \%$; Group 4: $30 \pm 8 \%$ ). Mean values ( \pm SEM) for the percentage of the intraparenchymal cartilaginous airway wall occupied by blood vessels, smooth muscle and cartilage is shown in table 2 . In Group 1 the percentage of the inner wall occupied by blood vessels was $15 \pm 1 \%$; this percentage was significantly higher $(24 \pm 4 \%$; $p<0.01)$ in Group 2 (histamine), but not different in Groups 3 (phenylephrine; $\mathrm{p}=0.3$ ), or Group 4 (methoxamine; $\mathrm{p}=0.07$ ). In Group 1 the percentage of the outer wall occupied by blood vessels was $21 \pm 2 \%$; this percentage was higher $(31 \pm 6 \%, p<0.01)$ in Group 2, but not different in Group 3 or Group 4. In Group 2, (histamine) the area occupied by blood vessels for the total airway wall was also significantly greater than the control group $(\mathrm{p}<0.01)$. There was no difference between groups in the percentage of the wall occupied by smooth muscle and cartilage.

When we examined the relationship between the square root of the airway wall area (inner, outer and total wall area) and the length of the internal perimeter, which we used as a measure of airway size $[17,18]$, there was no difference between the groups. Mean values for each group for the slopes and intercepts for these relationships and for the corresponding $\mathrm{R}^{2}$ value and range of $\mathrm{R}^{2}$ values are shown in table 3 . There was also no difference between the slopes of the relationship between $\mathrm{Pi}$ and $\mathrm{Ai}$ for the four groups.

Table 3. - Airway wall dimensions

\begin{tabular}{lcccc}
\hline & $\begin{array}{c}\text { Group 1 } \\
\mathrm{n}=67\end{array}$ & $\begin{array}{c}\text { Group 2 } \\
\mathrm{n}=37\end{array}$ & $\begin{array}{c}\text { Group 3 } \\
\mathrm{n}=75\end{array}$ & $\begin{array}{c}\text { Group 4 } \\
\mathrm{n}=87\end{array}$ \\
\hline Inner wall & & & & \\
Slope & 0.06 & 0.05 & 0.06 & 0.06 \\
Intercept & 0.27 & 0.42 & 0.31 & 0.33 \\
$\mathrm{R}^{2}$-value & 0.982 & 0.985 & 0.975 & 0.985 \\
$\mathrm{R}^{2}$-range & $0.877-0.996$ & $0.975-1.0$ & $0.941-0.981$ & $0.958-0.991$ \\
Outer wall & & & & \\
Slope & 0.18 & 0.18 & 0.16 & 0.19 \\
Intercept & 0.35 & 0.35 & 0.51 & 0.48 \\
$\mathrm{R}^{2}$-value & 0.964 & 0.984 & 0.960 & 0.976 \\
$\mathrm{R}^{2}$-range & $0.877-0.996$ & $0.958-1.0$ & $0.946-0.981$ & $0.958-0.991$ \\
Total wall & & & & \\
Slope & 0.19 & 0.19 & 0.18 & 0.20 \\
Intercept & 0.43 & 0.40 & 0.59 & 0.56 \\
$\mathrm{R}^{2}$-value & 0.972 & 0.986 & 0.960 & 0.979 \\
$\mathrm{R}^{2}$-range & $0.953-0.997$ & $0.961-1.0$ & $0.950-0.983$ & $0.964-0.992$ \\
\hline
\end{tabular}

Data are presented as mean values. Slope, intercept, $\mathrm{R}^{2}$-value and $\mathrm{R}^{2}$-range from relationship between airway internal perimeter versus square root of airway wall area (inner, outer and total). 


\section{Discussion}

The results of this study show that in normal sheep a considerable fraction of the tracheal and bronchial wall is occupied by blood vessels, and that during histamineinduced airway narrowing there is a $50 \%$ increase in this volume fraction in both the inner and outer bronchial walls. In contrast to histamine, inhaled alpha-agonists did not decrease the tracheal or bronchial blood flow or vascular volume fraction. Despite the increase in vascular volume observed in the sheep challenged with histamine, there was not a significant change in the slope relating total wall area to airway internal perimeter. This suggests that histamine did not produce measurable airway wall oedema, and also indicates that the increase in airway wall thickness due to congestion alone is insufficient to be detected by this method of analysis. These results do not support a major role for vascular congestion as a cause of airway narrowing, and suggest that smooth muscle shortening is the main mechanism responsible for bronchoconstriction.

A 50\% increase in vascular volume could increase airway resistance. We calculated the potential effect of this amount of vascular congestion, making the assumption that the entire increase in vascular volume would encroach upon the airway lumen. The results of this calculation are shown in figure 4 , in which airway size (Pi) is plotted against the calculated fold-increase in resistance. It is evident that for the larger airways, a doubling of bronchovascular volume would have a minimal effect on airway resistance. However this does not hold for the smaller airways, because of their relatively greater wall thickness. It can be seen in figure 4 that in airways having an internal perimeter of $<5 \mathrm{~mm}$ (the boundary between cartilaginous and membranous airways) there is a steep rise in the calculated increase in resistance. In this study, however, only $12 \%$ of the measured airways had internal perimeter of $<5 \mathrm{~mm}$ and we cannot be sure that the vessels occupy the same fractional area in smaller airways. The tissue was not good enough to allow us to make accurate measurements of airway vascular volume in the membranous airways. It is known that the wall thickness of noncartilaginous airways is greater than that of cartilaginous airways [18], so that a similar relative

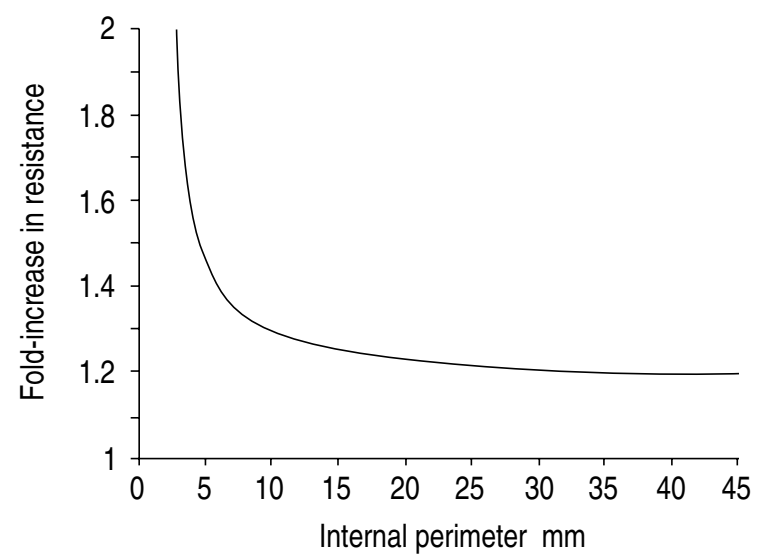

Fig. 4. - Potential effect of a $50 \%$ increase in vascular volume on airway resistance (see text for explanation). amount of vascular congestion in the smaller airway could have a more pronounced effect on airway resistance. Despite an increase in bronchial blood volume in the histamine group, there was no increase in tracheal blood volume. The tracheal blood occupied $>30 \%$ of the submucosal tissue, and it is possible that this represents maximal vasodilation.

JAMES et al. [17, 18] have shown that airway wall area remains constant during changes in lung volume and smooth muscle contraction; therefore, in the absence of any significant oedema or vascular congestion the relationship between $\mathrm{Pi}$ and the square root of the wall area remains constant. Therefore, an increase in intercept or slope of the relationship of Pi and wall area will give an indication of airway wall thickening. In our study, although histamine inhalation produced an increase in the volume fraction of the airway wall occupied by blood vessels, there was no evidence to suggest the presence of airway wall oedema, because when we examined the relationship between the square root of the airway wall area and the internal perimeter, there was no difference between the four groups. It may be that this method of assessing the presence of oedema is not sensitive enough for relatively small increases in oedema. By plotting the internal perimeter versus square root of wall area we should also be able to detect the wall thickening due to congestion. However, a $50 \%$ increase in the volume of a compartment that only occupies $18 \%$ of the wall could result in only a $9 \%$ increase in total wall area, which might be less than we can detect by this method. Alternatively, there could actually have been a redistribution of fluid from the airway wall interstitium to the vascular compartment. RUBINSKY et al. [20] have described such a shift in fluid between compartments in rapidly frozen liver. Fluid might shift from the interstitium to the vascular compartment if the blood froze first. During freezing, ice crystals would exclude solute and increase the osmolarity of the remaining intravascular fluid, causing water to move from the interstitial compartment into the vessels. If a similar phenomenon occurred in the bronchial walls, it would result in an apparent engorgement of bronchial vessels. However, if this artefact had occurred in our study, it would have effected all groups; therefore, it is unlikely to explain the difference in vascular volume seen in the histamine group. We believe that the methods we used to preserve vascular volume enabled us to trap all the pulmonary, tracheal and bronchial blood in the lung and airways. In the bronchial vessels, there could have been redistribution from the bronchial to the pulmonary vascular compartment through bronchopulmonary anastomoses.

To our knowledge, this is the first report to document the effects of altering bronchial vascular volume and blood flow on airway wall thickness, airway calibre and pulmonary resistance. LAITINEN et al. [6] have recorded an increase in mucosal thickness during perfusion of histamine into the dog's tracheal circulation, and a decrease in thickness after perfusion of the alpha-agonist, phenylephrine. However, the changes in mucosal thickness were small (usually not more than $100 \mu \mathrm{m}$ ). MARIASSY et al. [7] have reported the results of a study designed to determine the effects of altering tracheal and bronchial vascular 
volume on airway wall thickness and luminal diameter. However, they did not measure changes in airway blood flow or pulmonary resistance. They used morphometric techniques to quantitate the subepithelial (55 $\mu \mathrm{m}$ depth) microvascular volume fraction in the wall of the trachea and in 1.0 and $0.5 \mathrm{~mm}$ diameter bronchioles of sheep in the normal state and under conditions of "hyperaemia" (pulmonary hypertension and vasodilation). They perfused the bronchial vasculature with fixative at varying pressures under hyperaemic and normal states (with and without nitroprusside). Results showed that the microvasculature comprised from $12-16 \%$ of the subepithelial tissue volume, and that vascular congestion produced about a doubling of this volume fraction. Qualitatively, their results are similar to ours. Although, in our study the control values for the volume fraction were higher than theirs for the trachea (34\%) and for the cartilaginous airways (19\%), the increase due to vascular congestion was less. The reason for the differences in control values is probably related to the specific anatomical areas which were examined. Their study was designed to exclude the large venous sinusoids present in the sheep trachea and conducting airways [5], and our study was designed to include all vessels internal and external to the smooth muscle layer.

The results from this study do not support the indirect evidence from previous studies, which suggested that bronchial vascular dilation could contribute to airway narrowing [10-12]. This was based on the fact that there was attenuation of exercise-induced asthma after inhalation of methoxamine [10], an exacerbation of airflow obstruction after acute expansion of thoracic blood volume $[11,12]$. The results in the sheep showing minimal airway narrowing during bronchial vasodilation, and no vasoconstriction after inhalation of the alpha-agonists, suggest that the interventions may have produced their effects by other mechanisms.

It has been suggested that the airway obstruction associated with bronchiolitis may be secondary to vascular congestion, rather than to airway smooth muscle contraction. Results from recent studies in infants who had bronchiolitis [21] have shown a decrease in airway resistance after the children received nebulized epinephrine, but not after receiving nebulized salbutamol. However, there have been no direct measurements of airway blood flow or volume in subjects with this condition. Indeed, there are no data in humans or animals that have demonstrated a decrease in bronchial blood flow or volume after inhalation of alpha-agonists.

In the present study, we were surprised to find there was no change in bronchial blood flow or vascular volume after inhalation of the alpha-agonists, methoxamine and phenylephrine, as there is considerable evidence that alpha-receptors are present in bronchial vascular smooth muscle [22, 23].

There are several possible explanations to account for this absence of measurable vasoconstriction. One is that, in sheep, alpha-receptors may be located mainly on larger rather than smaller bronchial microvessels; if this were the case, then it is possible that phenylephrine or methoxamine, diffusing from the airway lumen, will not reach these larger bronchial vessels. In humans, alpha-recep- tors may be located preferentially on smaller vessels and, if so, this could account for the difference between the purported vasoconstriction caused by inhaled alpha-agonists in humans and its absence in sheep. Another possible explanation is that, in the presence of disease, there is novel expression of alpha-receptors on the bronchial microvessels. We also considered the possibility that vasoconstriction by alpha-agonists may only occur if the vessels are dilated. The non-dilated vessels in normal, healthy sheep might not respond to alpha-agonists, whereas asthmatics and patients in heart failure who "responded" to inhaled alpha-agonists may do so because they are already vasodilated. We think this latter explanation unlikely, however, because we have observed, in a separate group of sheep, a varying response to alphaagonists depending on the route of administration. In six sheep, in which we measured bronchial blood flow using a transonic flow probe placed around the common bronchial artery, there was a rapid reduction in bronchial blood flow of $64 \pm 10 \%$ (SD) on infusion of phenylephrine $\left(0.001 \mathrm{mg} \cdot \mathrm{ml}^{-1}\right.$ at a rate of $\left.1 \mathrm{ml} \cdot \mathrm{min}^{-1}\right)$ into the bronchial artery. However, when we administered increasing doses of phenylephrine as an aerosol (0.001, 0.1 and $10 \mathrm{mg} \cdot \mathrm{ml}^{-1}$ for $5 \mathrm{~min}$ each) to some of these sheep there was no reduction in bronchial blood flow.

In the present study, we are confident that a sufficient dose of agonist was administered, because we saw slight but significant rises in systemic arterial pressure during inhalation of the higher doses of phenylephrine $(10$ $\left.\mathrm{mg} \cdot \mathrm{ml}^{-1}\right)$ and methoxamine $\left(5 \mathrm{mg} \cdot \mathrm{ml}^{-1}\right.$ given in the pilot study). The aerosol of alpha-agonist was administered in the same way as the histamine aerosol, which had a pronounced vascular effect, indicating that delivery of the aerosol was not a problem. Conceivably, administration of alpha-agonists in aerosolized form could release a vasodilator substance from airway epithelial cells or another source, thereby counteracting its vasoconstrictor effect. Such an interactive mechanism has been proposed for beta-adrenoceptors located on epithelial cells and airway smooth muscle cells. Release of endothelial-derived relaxing factor can be activated by stimulation of beta-receptors on the epithelial cells [24].

We were surprised that we could not detect airway luminal narrowing in the histamine group when we examined the relationship between $\mathrm{Pi}$ and $\mathrm{Ai}$, despite the fact that the lungs were removed from the sheep and frozen quickly at the time of the peak response to histamine. The possible explanations for this are as follows:

1. That the airway narrowing which increased resistance was in airways peripheral to those that we sampled. For reasons of accuracy we measured the morphometric dimensions only in cartilaginous airways. It is possible that the major airway narrowing which caused the increase in resistance was in more peripheral airways.

2. That the airway smooth muscle shortening which occurred in vivo and caused increased resistance, relaxed during the freezing and subsequent fixation. In previous studies we have used rapid fixation in excised human [17], guinea-pig [18], and dog lungs [25], and have demonstrated airway luminal narrowing following the administration of bronchoconstricting agents. However, 
in this study the sheep were alive at the time of the bronchoconstriction and it is possible that it reversed much more quickly. We did everything to try to retain the airway geometry as it was at the time of the peak response to histamine, by having the chest open and ligatures in place around the left hilum and continuing to nebulize the histamine up until the moment of death of the sheep. However, it must take a finite amount of time for the airway tissues to freeze after removal of the lungs from the sheep, especially when the entire pulmonary and bronchial vascular blood volume exists as a heat sink. 3 . It could be that the increase in resistance is predominantly due to an increase in tissue resistance, not reflected in airway narrowing [26]. However, we measured airway resistance using a rapid oscillatory technique (frequencies between 4-6 Hz), which should reflect mainly airway rather than tissue resistance.

The failure to demonstrate significant luminal narrowing does not detract from the fact that we have shown vascular dilation in the histamine group. It does mean, however, that we cannot actually compare the degree of luminal narrowing due to vascular congestion with that due to smooth muscle shortening.

In summary, the results of this study indicate that vascular congestion is unlikely to play a major role in airway narrowing, at least in cartilaginous airways. Most of the increase in airflow resistance following inhalation of histamine is presumably due to airway smooth muscle contraction. These data also show a lack of vasoconstrictor response to inhaled alpha-agonists. This observation is relevant to the studies in which a protection against bronchoconstriction provided by alpha-agonists has been attributed to vasoconstriction.

Acknowledgements: The authors thank D. Minshal and L. Carter for their technical assistance and sense of humour; S. Greene for his photographic expertise; $\mathrm{H}$. Coxon for his patient help with the morphometric analysis; M. McLean and R. Talento for painstakingly processing the histological specimens, and $\mathrm{B}$. Wiggs for his invaluable help with the statistical analysis.

\section{References}

1. Pietra GG, Szidon JP, Leventhal MM, Fishman AP. Histamine and interstitial pulmonary edema in the dog. Circ Res 1971; 29: 323-337.

2. Magno MG, Fishman AP. Origin, distribution and blood flow of the bronchial circulation in anesthetized sheep. J Appl Physiol: Respirat Environ Exercise Physiol 1982; 53: 272-279.

3. Laitinen A, Laitinen LA, Moss R, Widdicombe JG. Organization and structure of the tracheal and bronchial blood vessels in the dog. J Anat 1989; 166: 133-140.

4. Hughes T. Microvascular circulation of the tracheobronchial tree. Nature 1965; 206: 425-426.

5. Hill P, Goulding D, Webber SE, Widdicombe JG. Blood sinuses in the submucosa of large airways of the sheep. $J$ Anat 1989; 162: 235-247.

6. Laitinen LA, Robinson NP, Laitinen MA, Widdicombe JG. Relationship between tracheal mucosal thickness and vascular resistance in dogs. J Appl Physiol 1986; 61: 2186-2194.

7. Mariassy AT, Gazeroglu H, Wanner A. Morphometry of the subepithelial circulation in sheep airways. Effect of vascular congestion. Am Rev Respir Dis 1991; 143: 162-166.

8. Kuwano K, Bosken CH, Paré PD, Bai TR, Wiggs BR, Hogg JC. Small airways dimensions in asthma and chronic obstructive pulmonary disease. Am Rev Respir Dis 1993; 148: 1220-1225.

9. James A, Kan R, Carroll N. Bronchial blood vessel dimensions in asthma. Am Rev Respir Dis 1993, 147: A455.

10. Dinh Xuan AT, Chaussain M, Regnard J, Lockhart A. Pretreatment with an inhaled alpha-adrenergic agonist, methoxamine, reduces exercise-induced asthma. Eur Respir J 1989; 2: 409-414.

11. Regnard J, Baudrillard P, Salah B, Dinh Xuan T, Cabanes $\mathrm{L}$, Lockhart A. Inflation of antishock trousers increases bronchial response to methacholine in healthy subjects. J Appl Physiol 1990; 68: 1528-1533.

12. Gilbert IA, Regnard J, Lenner KA, Nelson JA, MacFadden ER Jr. Intrathoracic airstream temperatures during acute expansion of thoracic blood volume. Clin Sci 1991; 81: 655-661.

13. Cabanes LR, Weber SN, Matran R, et al. Bronchial hyperresponsiveness to methacholine in patients with impaired left ventricular function. $N$ Engl J Med 1989; 320: 1317-1322.

14. Sasaki F, Ishizaki T, Mifune J, Fujimura M, Nishioka S, Miyabo S. Bronchial hyperresponsiveness in patients with chronic congestive heart failure. Chest 1990; 97: 534-538.

15. Mead J and Whittenberger JL. Lung inflation and hemodynamics. In: Handbook of Physiology. Respiration, Washington DC, Am Physiol Soc 1964; Sect. 3, Vol. I, Chapt. 18, pp. 477-486.

16. Baile EM, Nelems JMB, Schulzer M, Paré PD. Measurement of regional bronchial arterial blood flow and bronchovascular resistance in dogs. J Appl Physiol: Respirat Environ Exercise Physiol 1982; 53: 1044-1049.

17. James AL, Hogg JC, Dunn LA, Paré PD. The use of the internal perimeter to compare airway size and to calculate smooth muscle shortening. Am Rev Respir Dis 1988; 138: 136-139.

18. James AL, Paré PD and Hogg JC. Effects of lung volume, bronchoconstriction and cigarette smoke on morphometric airway dimensions. J Appl Physiol 1988; 64: 913-919.

19. Feldman HA. Families of lines: random effects in linear regression analysis. J Appl Physiol 1988; 64: 1721-1732.

20. Rubinsky B, Lee CY, Bastacky J, Onik G. The process of freezing and the mechanism of damage during hepatic cryosurgery. Cryobiology 1990; 27 85-97.

21. Sanchez I, De Koster J, Powell R, Wolstein R, Chernick $\mathrm{V}$. Inhaled epinephrine is better than salbutamol for treatment of infants with bronchiolitis. Am Rev Respir Dis 1993; 147: A133.

22. Lung MA, Wang JC, Cheng KK. Bronchial circulation: an autoperfusion method for assessing its adrenoceptors in the bronchial artery. Life Sci 1976; 19: 577-580.

23. Widdicombe JG, Webber SE. Neuroregulation of the tracheobronchial circulation. In: Butler J, ed. Lung Biology in Heatlh and Disease. The Bronchial Circulation. Chp 8, New York, Dekker, 1992; p. 257.

24. Vanhoutte PM. Epithelium-derived relaxing factor(s) and bronchial reactivity. Am Rev Respir Dis 1992; 138: S24-S30.

25. Okazawa M, Bai TR, Wiggs B, Paré PD. Airway smooth muscle shortening in excised canine lung lobes. $J$ Appl Physiol 1993; 74: 1613-1621.

26. Ludwig MS, Shore SA, Fredberg JJ. Differential responses of tissue viscance and collateral resistance to histamine and leukotriene $\mathrm{C}_{4}$. J Appl Physiol 1988; 65: 1424. 